Research Article

\title{
Static Load Test on Trapezoidal Filling Structure of Crushed Concrete Particles Reinforced with Waste Tire Slices
}

\author{
Fang Tong, ${ }^{1}$ Qiang $\mathrm{Ma}{ }^{\mathbb{D}},{ }^{2}$ Bin $\mathrm{Hu}^{2}$ and Zhenyi Zheng ${ }^{2}$ \\ ${ }^{1}$ Hubei University of Technology Engineering and Technology College, Department of Biochemical Engineering, \\ Wuhan 430068, China \\ ${ }^{2}$ Hubei University of Technology, School of Civil Engineering and Architecture, Wuhan 430068, China \\ Correspondence should be addressed to Qiang Ma; maqiang927@163.com
}

Received 26 August 2021; Revised 29 October 2021; Accepted 5 November 2021; Published 24 November 2021

Academic Editor: Yi Zhang

Copyright (C) 2021 Fang Tong et al. This is an open access article distributed under the Creative Commons Attribution License, which permits unrestricted use, distribution, and reproduction in any medium, provided the original work is properly cited.

In this paper, a series of model tests about the trapezoidal filling structures filled with tire reinforced concrete particles has been conducted to study their stability and the ultimate bearing capacity. The effects of the reinforcing tire slices on the global stability and ultimate bearing capacity of the model were investigated, the results show that the tire slices reinforcement can reduce the total settlement of the trapezoidal filling structure, and the ultimate bearing capacity of the reinforced trapezoidal filling structure with tire slices is obviously improved. Among them, the settlements of crushed concrete particles reinforced with bottom layer, top layer, and two layers (both bottom layer and top layer) waste tire slices are $11.5 \%, 37.7 \%$, and $46.2 \%$ less than that of unreinforcement, respectively. Compared with unreinforcement, when the top layer of the model is reinforced with tire slices, the Earth pressure values at the top layer and the bottom layer are reduced by $21.1 \%$ and $22.7 \%$, respectively; the Earth pressure values at the top layer and the bottom layer are reduced $6.3 \%$ and $14.3 \%$, respectively, when the bottom layer of the model is reinforced with tire slices, and the Earth pressure values at the top layer and the bottom layer are reduced $23.4 \%$ and $32.9 \%$, respectively, when the two layers of the model are reinforced with tire slices. The sliding surface of the pure concrete particles filled trapezoidal structure is continuous and runs through the whole trapezoidal filling structure slope; the sliding zone of reinforced trapezoidal filling structure with tire slices decreases with the laying of tire slices.

\section{Introduction}

Reinforced soil has been rapidly applied in geotechnical engineering of highway and railway construction. In highway construction, there are a great many of reinforcements, in which geogrids are commonly used as a reinforcement material; it can restrain the lateral deformation of embankment soil and change the stress state in the reinforcement to improve the stability of the embankment. Meanwhile, waste tires are proposed to be used as lightweight filling materials for road construction. Under the conditions of field performance test and numerical simulation, the research shows that the embankment exhibits good load-bearing performance [1-7]. Therefore, many scholars have done further research on tire reinforcement. $\mathrm{Wu}$ et al. [8] conducted a series of triaxial compression tests on 5 kinds of waste tire products with different gradations and different particle shapes and determined their shear strength, and the limit internal friction angles of the 5 kinds of waste tire products were between $45^{\circ}$ and $60^{\circ}$. Ghazavi [9] demonstrated how the shear strength characteristics of sand mixed with waste tires, rubber, and plastics in different proportions changed. The shear strength of different mortar specimens was compared, and two compaction states were considered. The results show that the main factors affecting the shear strength of sand-rubber mixtures are normal stress, unit weight of mixtures, and rubber content. Hataf [10] investigated the effect of the using of shredded waste tires as reinforcement to increase the bearing capacity of soil through a series of laboratory model tests. The results show that the bearing capacity ratio (BCR) increases with the increase of shear deformation. However, an optimum value 
for BCR is observed after that increasing shear deformation led to a decrease in BCR. Venkatappa Rao [11] evaluated the performance of additives, and the compressibility and triaxial compression tests were carried out by changing the size and the content of tire slices. The test results show that the content of sand-tire gravel mixture is about $20 \%$, which can be used as potential material for construction of a highway embankment with the height of $10 \mathrm{~m}$.

The change of physical properties of tire derived aggregate and rubber mixture has different degrees of influence on geotechnical and foundation engineering. Therefore, it is very meaningful to study and optimize the application of these materials. Wartman et al. [12] studied the real-time compression and time-dependent compression of tire derived aggregates (TDA) and TDA-soil composites. The result shows that the direct compression of TDA is almost entirely caused by the decrease of pore volume, which increases with the increase of TDA content and tire particle size. In recent years, many scholars introduced the characteristics of TDA through model test, field test, and numerical simulation, including compressive properties, lateral Earth pressure coefficient at rest and Poisson's ratio, immediate compression, and time-varying compression. The compression and load deformation performances of TDA in embankment were studied. The results show that TDA has better compressibility. Compared with the embankment without TDA, the peak settlement of the embankment is reduced by $17.21 \%$ and the failure load of the embankment increases by $24.78 \%$ by adding $10 \%$ TDA, which shows that the properties of tirederived aggregates have a good effect on engineering applications [13-18]. In order to improve concrete properties, Khaloo et al. [19] investigated the feasibility of using tirerubber particles composed of tire slices, crumb rubber as aggregate in concrete. The results show that it can improve the toughness of concrete. In highway construction, tire rubber-filled concrete is a kind of new cement concrete with a portion of aggregates replaced by waste tire rubber particles, many experimental studies were conducted to examine the potential of the tire rubber-filled concrete, and the tire rubber-filled concrete for pavement applications was evaluated for their performance. It is found that the tire rubber-filled concrete has very high toughness to support vehicle load [20-23]. In addition, there are many studies on crushed concrete particles reinforced with tire slices, Sandra L. et al. [24] added crushed tire particles as an aggregate in the concrete mixture to improve concrete properties and evaluated mechanical behavior of concrete specimens prepared with different amounts crushed tire particles, which partially replaced the fine aggregate, under an indirect tensile test. The results show that the specimens with $5 \%$ crushed tire particles present the highest value in direct tensile strength of 4.36 MPa. Ma et al. [25] carried out a series of shear tests to study the mechanical properties of tire slices reinforced crushed concrete particles. The results show that the addition of tire slices can increase the internal friction angle and cohesion of concrete particles and therefore increase the shear strength of crushed concrete particles.

Based on the above research, it is of practical significance to study the use of different waste tires to reinforce the backfill in highway construction. In this paper, a series of model tests about trapezoidal filling structures filled with waste tire reinforced concrete particles has been conducted to investigate the effect of the reinforcing tire slices on the global stability and ultimate bearing capacity of the trapezoidal filling structure. Detailed results are presented and discussed in the following sections.

\section{Test Method}

\subsection{Test Device}

2.1.1. Data Acquisition Instrument. As shown in Figure 1, it was a miniature Earth pressure cell called XTR-2030; as shown in Figure 2, it was a static strain test analyzer called TST3826 E for data acquisition.

2.1.2. Test Equipment. The test device was a self-made model test equipment. As shown in Figure 3, it was mainly composed of model test box, loading plate, and weights used for loading.

The size of the test box was $800 \times 400 \times 500 \mathrm{~mm}$, and the test box was made of transparent organic glass with a thickness of $15 \mathrm{~mm}$, which made it easy to observe the deformation of the model from any direction. In order to make the load acting on the top of the road trapezoidal filling structure uniformly, organic glass plate was used for loading. The size of loading plate was $390 \times 300 \mathrm{~mm}$, and its thickness was $15 \mathrm{~mm}$. Two steel bars were fixed around the sides of the test box to ensure that there was no obvious deformation. Vertical load was loaded by weights of $5 \mathrm{~kg}$ and $10 \mathrm{~kg}$. The trapezoidal filling structure model is shown in Figure 4.

\subsection{Measurement of Material Parameter}

2.2.1. Particle Screening Method. According to the relevant provisions of "highway geotechnical test regulations" (JTG E40-2017), the content of each particle group is determined. The composition of concrete particles should be represented by the coefficient of unevenness $\left(C_{u}\right)$ and the coefficient of curvature $\left(C_{c}\right)$ of the gradation index. $C_{u}$ and $C_{c}$ can be calculated by the following formulas:

$$
\begin{aligned}
& C_{u}=\frac{d_{60}}{d_{10}}, \\
& C_{c}=\frac{d_{30}^{2}}{d_{60} d_{10}},
\end{aligned}
$$

where $d_{60}$ is constrained grain size, that is, the particle size $(\mathrm{mm})$ in the soil with a mass less than $60 \%$ of this particle size; $d_{10}$ is effective grain diameter, that is, the particle size $(\mathrm{mm})$ in the soil with a mass less than $10 \%$ of this particle size; $d_{30}$ is the particle size $(\mathrm{mm})$ in the soil with a mass less than $30 \%$ of this particle size.

During the test, the compactness of concrete particles was controlled by the compaction, and a small rammer was used for compaction. The falling distance was the same when the hammer strikes, and the layered filling of $100 \mathrm{~mm}$ was 


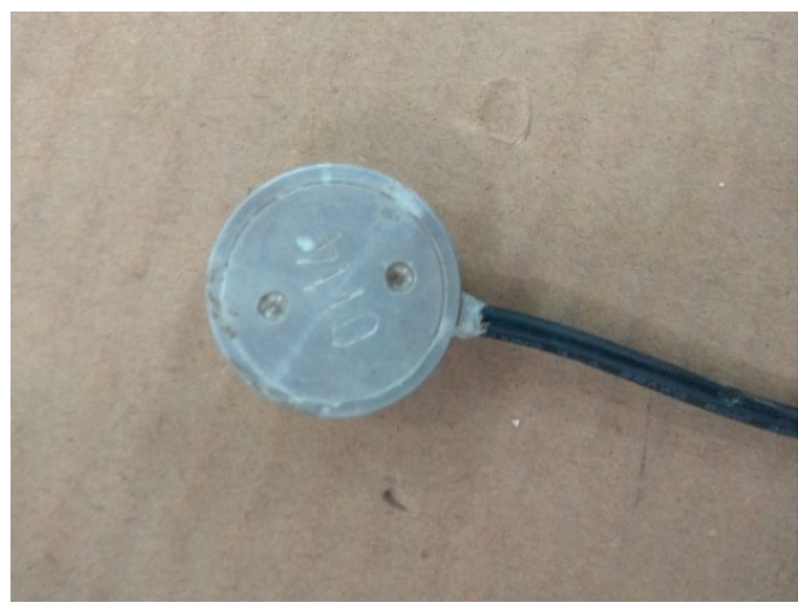

Figure 1: Miniature Earth pressure cell.

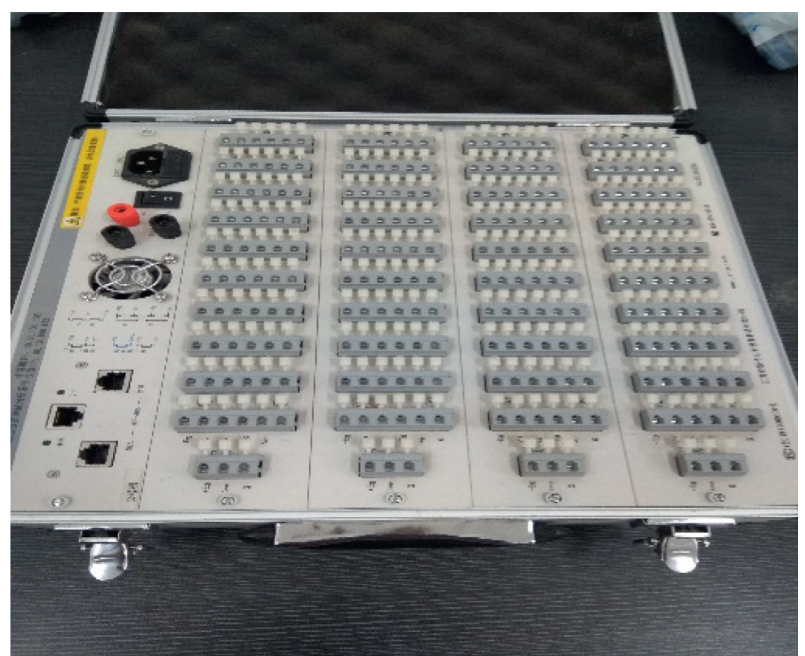

Figure 2: Static strain test analyzer instrument.

carried out. The compactness of trapezoidal filling structure was measured before loading. The method of measuring the compactness was to randomly select 3 samples at different positions of the trapezoidal filling structure and took the average value of compactness; the final relative compactness was 0.45 .

2.2.2. Placement of Micro-Earth Pressure Cell. Due to the concrete particles having sharp corners, it is easy to damage the micro-Earth pressure cell when subjected to vertical loads. Therefore, a cotton cloth was wrapped around the micro-Earth pressure cell, and standard sand was filled underneath the micro-Earth pressure cell. In this way, not only the micro-Earth pressure cell was protected, but also the external force was transmitted uniformly to the surface of the Earth pressure cell through sand. The micro-Earth pressure cells were arranged in two layers (top layer and bottom layer). Five micro-Earth pressure cells (named A, B, $\mathrm{C}, \mathrm{D}$, and $\mathrm{E}$ ) were arranged in each layer along the longitudinal line, and a control micro-Earth pressure cell (named

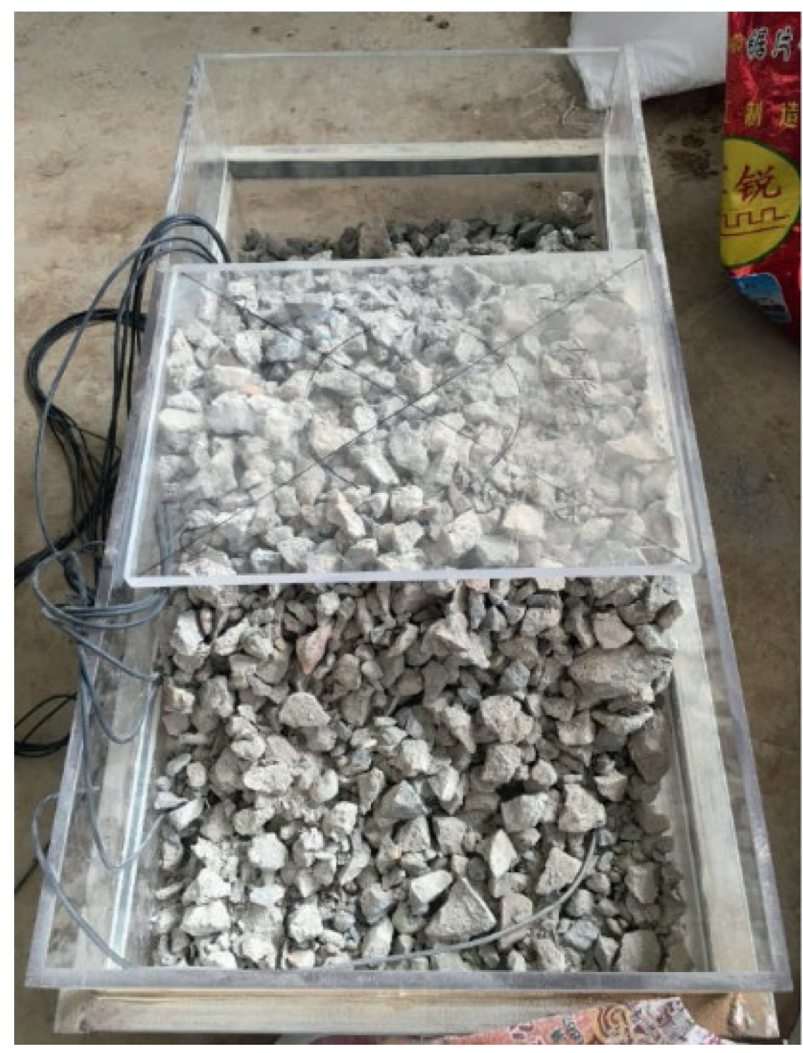

Figure 3: Model test box.

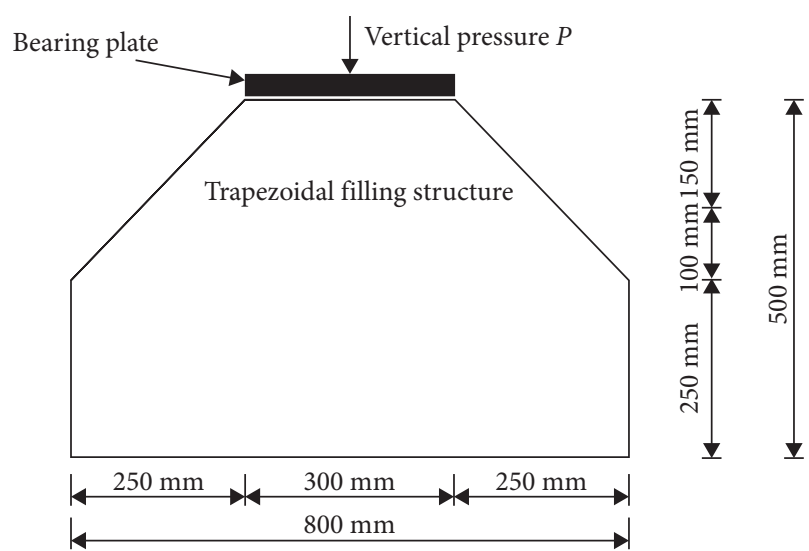

Figure 4: Diagram of trapezoidal filling structure.

F) was arranged along the transverse line, as shown in Figure 5.

As shown in Figures 6(a) and 6(b), the Earth pressure cells (named A2, B2, C2, D2, E2, and F2) were installed below the bottom layer of tire slices, while the corresponding Earth pressure cells (named A1, B1, C1, D1, E1, and F1) were installed below the top layer of tire slices.

2.3. Test Conditions. As shown in Figure 6(a), the height of the trapezoidal filling structure in the test was $500 \mathrm{~mm}$, the distance from the top layer of tire slices to the pavement was $150 \mathrm{~mm}$, and the distance from the bottom layer of tire slices 


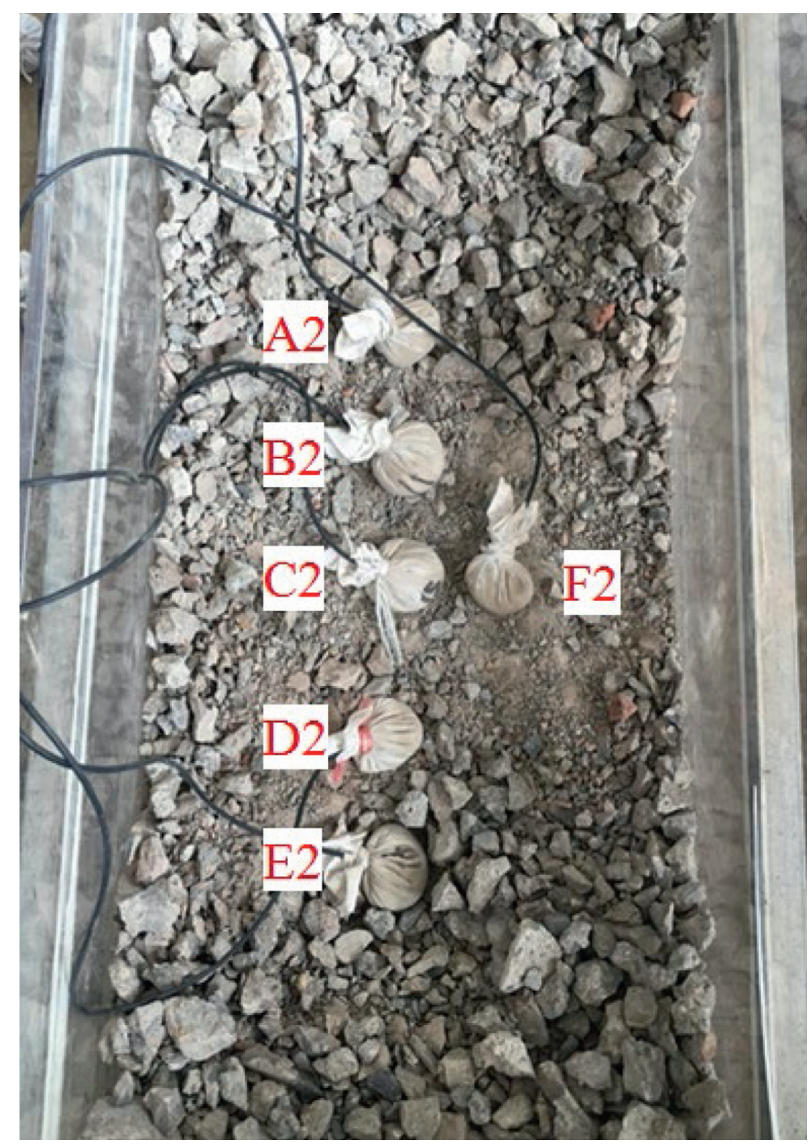

Figure 5: Schematic layout of one-story Earth pressure cells.

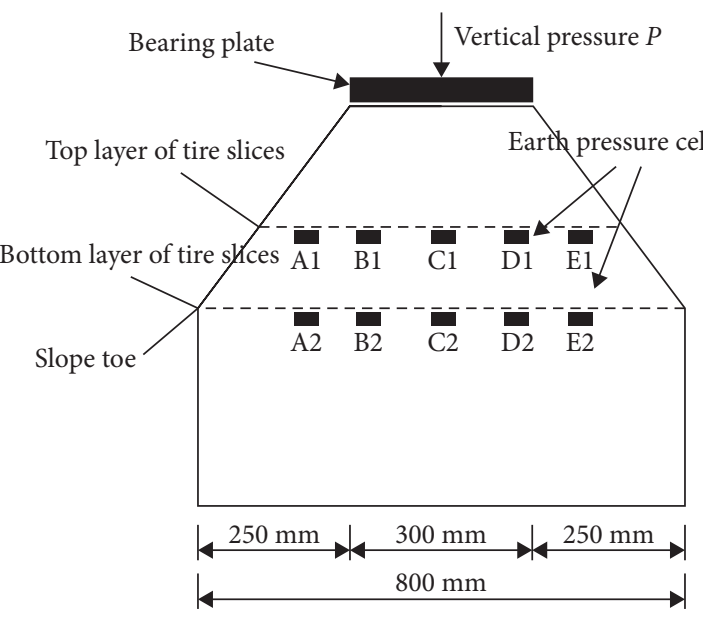

(a)

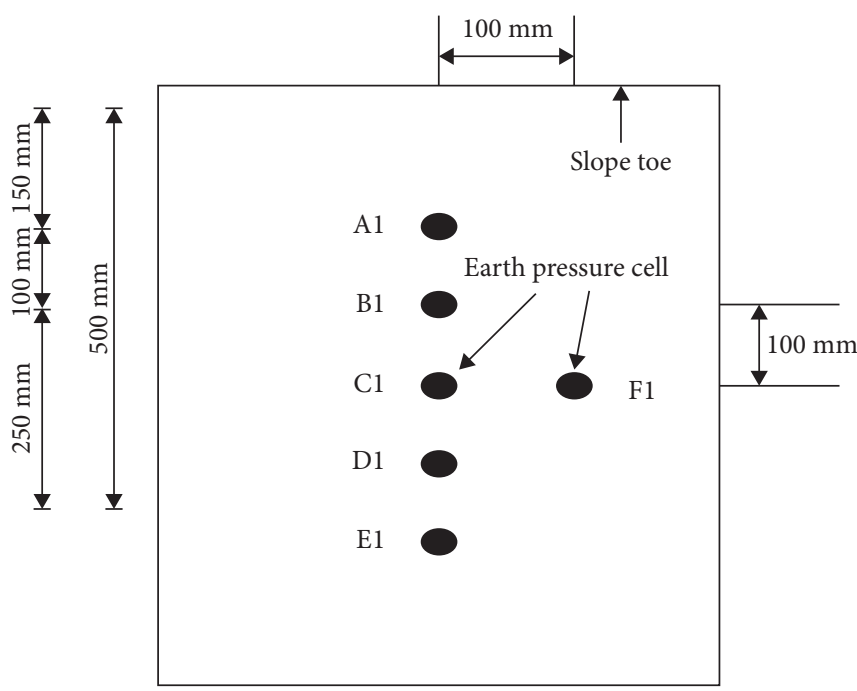

(b)

Figure 6: Layout of Earth pressure cells placement. (a) Section view. (b) Plan view.

to the top layer was $100 \mathrm{~mm}$. The testing conditions are shown in Table 1. The laying position of the tire slices is shown in Figures 6(a) and 6(b), and the method to lay a layer of tire slices is shown in Figure 7.
2.4. Parameters to be Measured. The parameters to be measured in this test were the vertical pressure $P$ on the top of the bearing plate (the applied load) and the Earth pressures beneath the top layer and the bottom layer of the tire 
TABle 1: Testing conditions.

\begin{tabular}{lc}
\hline Testing condition & Arrangement of tire slices \\
\hline Testing condition A & No tire slices \\
Testing condition B & Single top layer of tire slices \\
Testing condition C & Single bottom layer of tire slices \\
Testing condition D & Both top and bottom layers of tire slices
\end{tabular}

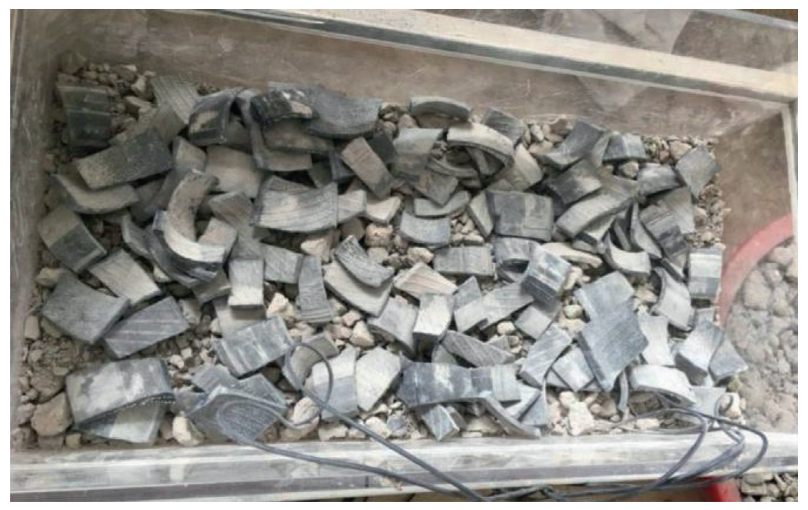

Figure 7: Laying of tire slices.

slices. The deformations of the trapezoidal filling structures after loading were continuously monitored.

\subsection{Test Method. The test comprises the following steps:}

(1) Filling of trapezoidal filling structure model was as follows: layered filling method was used and the tire slices were laid, every $10 \mathrm{~cm}$ was compacted once to achieve the required compactness, and the displacement reading reference object was embedded in the position where the tire slices were laid.

(2) Setting of load value was as follows: the load set in this test was $2 \mathrm{kPa}$ per stage. The next stage load was loaded after the deformation of the model was stable. The required load and the loading time for each stage load were set. Due to the slow deformation of concrete particles, the loading time of each stage was set to be 5 minutes.

(3) Data measurement was as follows: because the loading time was 5 minutes, the deformation of the model was observed through a microscope in the process of loading, and the deformation of the model was recorded at regular intervals. After the deformation of the model was stable, the load was applied. During this process, the deformation of the trapezoidal filling structure slope was photographed with a camera, and the load was continuously applied until the failure of trapezoidal filling structure.

(4) Test results analysis was as follows: the deformation data of the model can be obtained by calculating and processing the recorded coordinates; then, the deformation curve was drawn, and the stability of the model, the performance of tire slices, and the effect of its reinforcement on the Earth pressure were analyzed.
2.6. Terminate Loading Condition. Vertical pressure was applied by weights. The maximum loading pressure was $10 \mathrm{kPa}$. As shown in Figure 8, each stage of load was set to be $2 \mathrm{kPa}$, and the loading time of each stage depended on the deformation of the trapezoidal filling structure. When the model was stable (each stage load was loaded for about 5 minutes), the next stage load was applied until the trapezoidal filling structure is obviously deformed. The sliding failure of trapezoidal filling structure slope was regarded as the termination condition of loading.

\section{Test Results and Analysis}

3.1. Effect of Tire Slices Reinforcement on Settlement. The load-settlement $(P-S)$ curves at the axis of pure concrete particles filled trapezoidal structure and trapezoidal filling structure of concrete particles reinforced with tire slices are shown in Figure 9. Through comparative analysis, it can be seen that all $P-S$ curves almost change linearly in the early stage of load, while in the later stage, the curves become steeper and the settlement increases rapidly. The results show that with the increase of the applied load, the particles in the slope of trapezoidal filling structure are stable after relative movement. When the applied load continues increasing, the trapezoidal filling structure finally loses its stability and slides. The inflection point of $P-S$ curve of pure concrete granular filled trapezoidal structure is more obvious than that of trapezoidal filling structure reinforced with waste tire slices. Compared with pure concrete granular filled trapezoidal structure, it can be seen that deformation tolerance of trapezoidal filling structure reinforced with waste tire slices is increased, which makes the failure mode of the trapezoidal filling structure change from punching and local shear failure to overall shear failure.

As shown in Figure 9, it can be seen that the settlements under four testing conditions show a linear growth state at the beginning and then increase with the increases of load; the growth of the settlements is the fastest of testing condition $\mathrm{A}, \mathrm{C}$ is the second, $\mathrm{B}$ is the third, and $\mathrm{D}$ is the slowest. While the settlement of testing condition $D$ increases slowly and tends to be stable gradually. Compared with testing condition A, it can be seen from Figure 9 that from the beginning of load to the destruction, the settlement of testing condition $\mathrm{C}$ is reduced by $11.5 \%$, the settlement of testing condition B is reduced by $37.7 \%$, and the settlement of testing condition $D$ is reduced by $46.2 \%$. The settlement of testing condition $\mathrm{C}$ is larger than that testing condition $\mathrm{B}$, because the larger deformation of the inner part of the trapezoidal filling structure slope is mainly concentrated on the upper part of the slope and followed by the lower part of the slope, the model reinforced with tire slices which can limits the deformation of the slope. Compared with the bottom layer of the model reinforced with tire slices, the interaction between concrete particles and tire slices is greater when the top layer of the model is reinforced with tire slices. Therefore, it indicate that the effect of the top layer of the model reinforced with tire slices is better than the bottom layer of the model reinforced with tire slices, and both of them are better than those without reinforcement. 


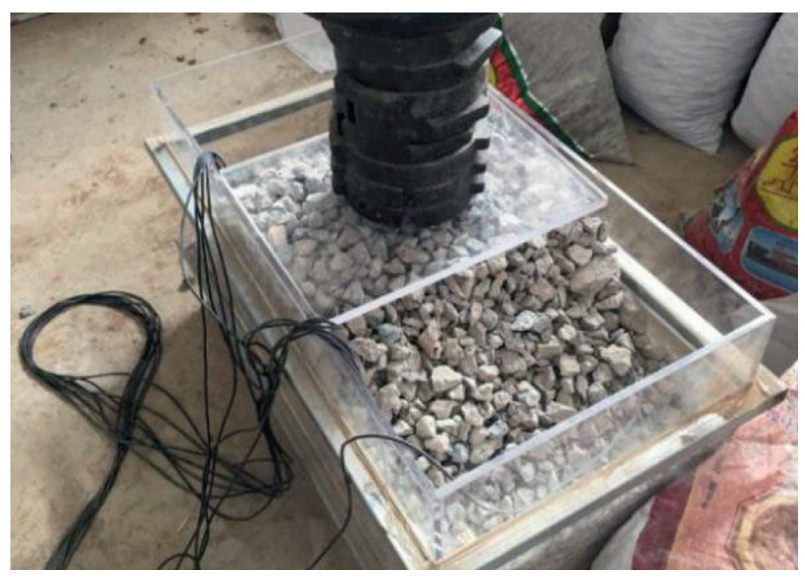

FIGURE 8: Loading of weights.

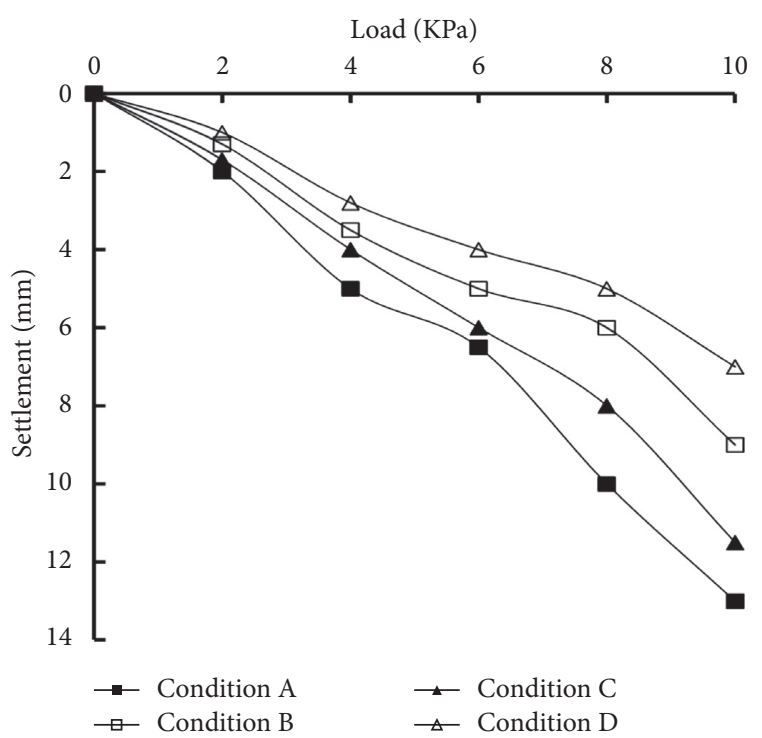

FIgURE 9: $P-S$ curve of trapezoidal filling structure axis under four testing conditions.

The effect of two layers (both top and bottom layers) reinforced with tire slices is best.

As shown in Figure 10, it can be seen that the settlements of trapezoidal filling structure toe of slope under four testing conditions all increase at the beginning and show a linear growth state when load is less than $2 \mathrm{kPa}$. When the load range is from $2 \mathrm{kPa}$ to $8 \mathrm{kPa}$, the settlement of the model toe of slope rapidly increases with the increase of the load under testing conditions $\mathrm{A}$ and $\mathrm{C}$ but slowly increases with the increase of load under testing conditions $B$ and D. The growth of the settlements is the fastest of testing condition $\mathrm{A}$, $\mathrm{C}$ is the second, $\mathrm{B}$ is the third, and $\mathrm{D}$ is the slowest, while the settlement of testing conditions B, C, and D increases slowly and tends to be stable gradually, when the load reaches $10 \mathrm{kPa}$. Compared with testing condition $\mathrm{A}$, it can be seen from Figure 10 that the settlement at toe of slope under testing condition $\mathrm{C}$ is reduced by $9.2 \%$, the settlement at toe of slope under testing condition B is reduced by $30.8 \%$, and

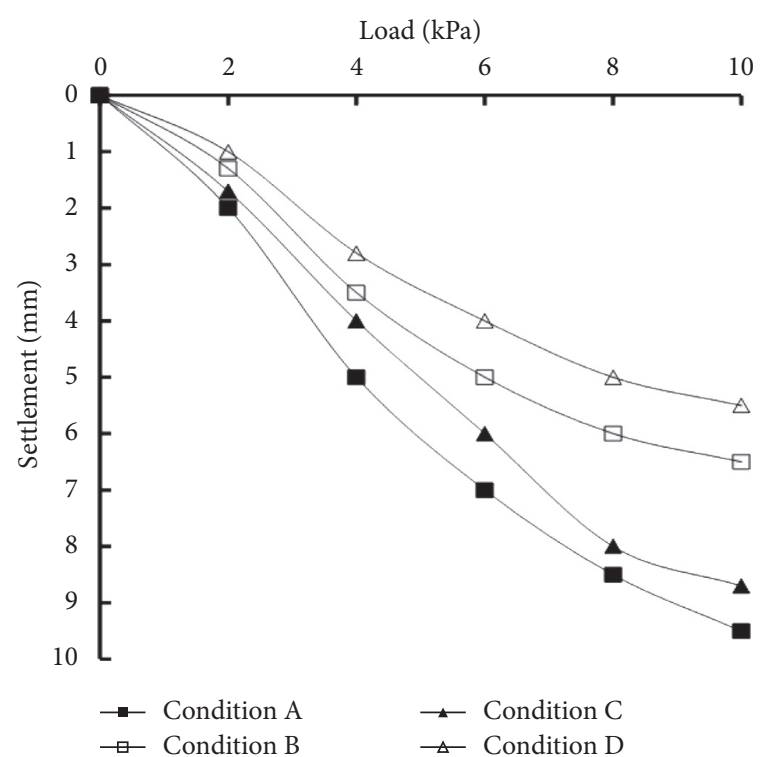

FIgURE 10: P-S curve at trapezoidal filling structure toe of slope under four testing conditions.

the settlement at toe of slope under testing condition $D$ is reduced by $42.3 \%$.

Compared with the settlement of trapezoidal filling structure toe, the settlements of trapezoidal filling structure axis under each testing conditions are larger, the main reasons are as follows: the pressure on concrete particles at the toe of the slope is relatively small, and the wrapping force of the tire slices can reduce the additional stress transmitted by the particles at the central axis. By comparing the curves in Figures 9 and 10, it can be concluded that when the vertical load is the same, the settlement of the same layer of spread tire slices is nonuniform at different locations; the closer to the central axis, the greater the settlement, and the smaller the settlements at the toe of the slopes. The settlement is different when the tire slices are laid in different layers, the settlement is at the minimum when the tire slices is laid in two layers, and the differential settlement in different testing conditions is also increasing with the increase of load. When the load is the same, the settlement of testing conditions $\mathrm{B}$ and $\mathrm{C}$ is numerically calculated, and the testing condition B is $14 \%-30 \%$ smaller than that of the testing condition $\mathrm{C}$, while the settlement value is close at the slope toe.

3.2. Effect of Reinforcement on Earth Pressure. Compared with the pure concrete particles filled trapezoidal structure, the distribution of additional stress in the reinforced trapezoidal filling structure also changes greatly. The distribution of additional stress on the top and the bottom layers of the trapezoidal filling structure under $8 \mathrm{kPa}$ load is taken as an example. As shown in Figure 11, the distribution of the model additional stress under four cases is approximately parabolic.

It can be seen from Figure 11 that the Earth pressures without reinforcement decrease with the increase of the 


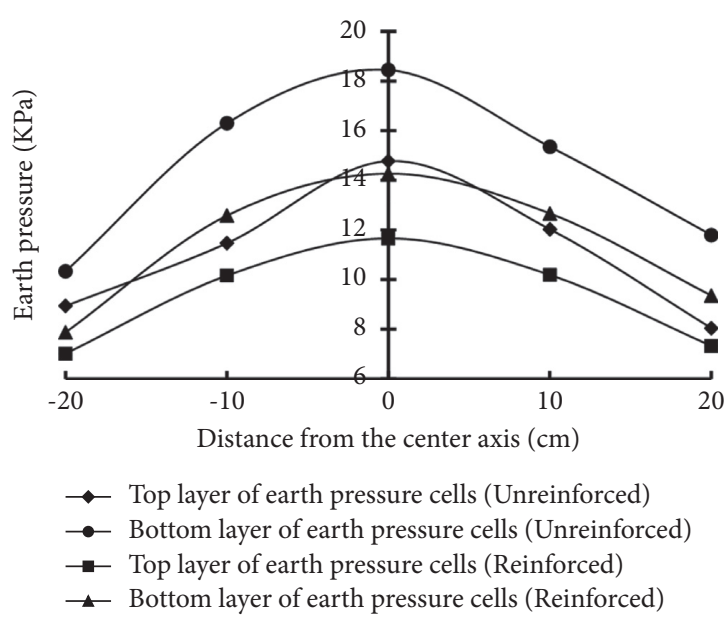

(a)

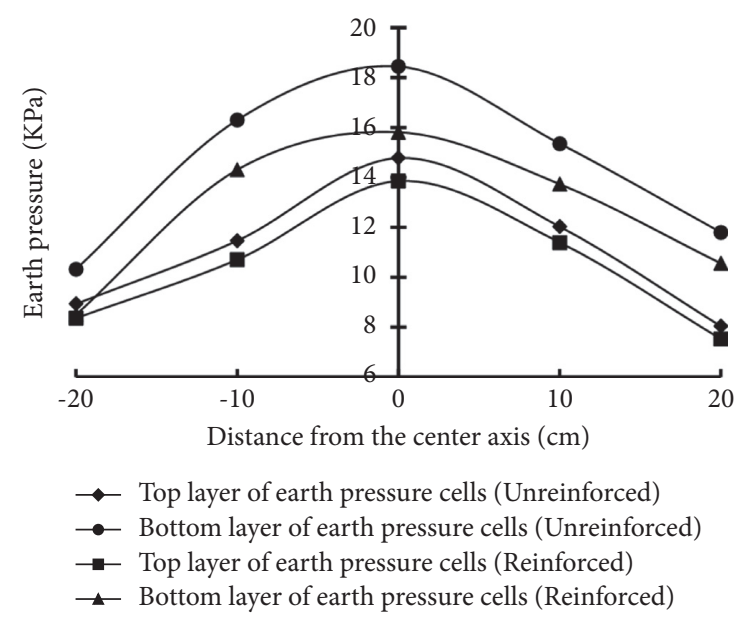

(b)

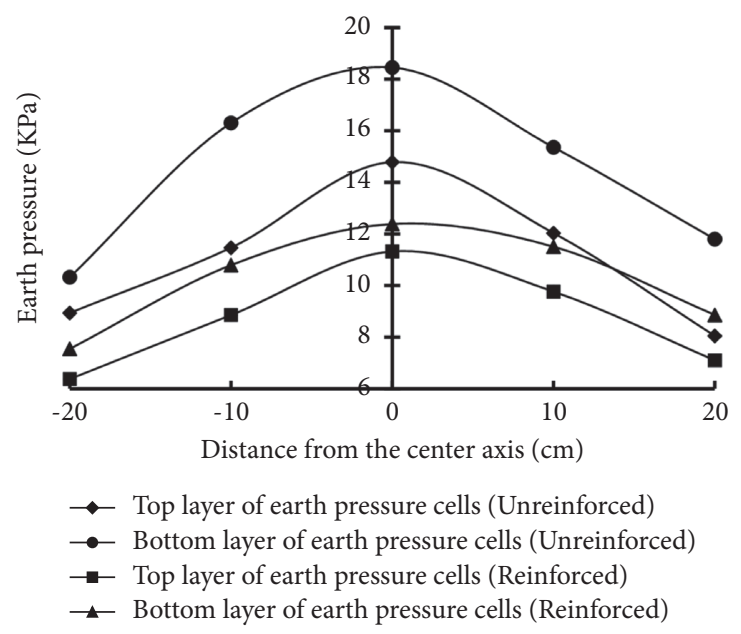

(c)

FIGURE 11: Earth pressures in trapezoidal filling structure. (a) Single top layer reinforced with tire slices. (b) Single bottom layer reinforced with tire slices. (c) Both top and bottom layers reinforced with tire slices.

distance from the central axis, and the changes of Earth pressures on both sides of the central axis are symmetrical. From Figure 11(a), under the condition of the top layer reinforced with tire slices, it can be seen that both top and bottom layer of Earth pressures decrease with the increase of the distance from the central axis. From Figure 11(b), under the condition of the bottom layer reinforced with tire slices, it shows that both top and bottom layer of Earth pressures decrease with the increase of the distance from the central axis. From Figure 11(c), under the condition of two layer reinforced with tire slices, it can be seen that both top and bottom layer of Earth pressures also decrease with the increase of the distance from the central axis.

As shown in Figure 11, the additional stresses of Earth pressure cells $\mathrm{C} 1$ and $\mathrm{C} 2$ located at the central axis are the highest; the values are $14.78 \mathrm{kPa}$ and $18.45 \mathrm{kPa}$ without reinforcement, respectively. The Earth pressure values $(\mathrm{C} 1$ and $\mathrm{C} 2$ ) are $13.85 \mathrm{kPa}$ and $15.81 \mathrm{kPa}$, respectively, when the bottom layer is reinforced with tire slices, the Earth pressure values $(\mathrm{C} 1$ and $\mathrm{C} 2)$ are $11.66 \mathrm{kPa}$ and $14.27 \mathrm{kPa}$ when the top layer is reinforced with tire slices, and the Earth pressure values $(\mathrm{C} 1$ and $\mathrm{C} 2)$ are $11.27 \mathrm{kPa}$ and $12.38 \mathrm{kPa}$ when two layers (both the bottom and top layers) are reinforced with tire slices. As shown in Figures 11(a)-11(c), compared with unreinforcement, the Earth pressure values of $\mathrm{C} 1$ and $\mathrm{C} 2$ located at the central axis decreased by $6.3 \%$ and $14.3 \%$ under the bottom layer of tire slices reinforcement condition, decreased by $21.1 \%$ and $22.7 \%$ under the top layer reinforcement condition, and decreased by $23.4 \%$ and $32.9 \%$ under the two layers reinforcement condition. It indicates that the effect of two layers tire slices reinforcement is the best, the effect of top layer reinforcement is better than that of the bottom layer reinforcement, and the effect of singlelayer reinforcement is better than those without reinforcement. The main reasons are listed as follows.

Due to the trapezoidal filling structure reinforced with tire slices, the diffusion angle of the additional stress increases. In the process of load transferring additional stress to trapezoidal filling structure, the distribution range of additional stress is enlarged, and the distribution range of additional stress is the largest under the testing condition $D$ (two layers reinforced with tire slices), testing condition B 
(top layers reinforced with tire slices) is the second, testing condition $\mathrm{C}$ (bottom layers reinforced with tire slices) is the third, and testing condition A (without reinforcement) is the smallest. The distribution of additional stress in trapezoidal filling structure is more uniform. Compared with the bottom layer reinforced with tire slices, under the top layer reinforced with tire slices, the greater reaction force and wrapping force of the concrete particles will be generated at the bottom plane, when it supports the pressure transmitted from the upper part of the concrete particles. The additional stress and its difference of both pure concrete trapezoidal filling structure and waste tire slices reinforced trapezoidal filling structure decrease with the increase of trapezoidal filling structure depth. It can be seen from the experimental results that the dispersion effect of tire slices on the additional stress is mainly concentrated in the vicinity of the tire reinforcement, and the dispersion effect is small in the area far from it.

\subsection{Effect of Reinforcement on Stability. Concrete granular} reinforced with tire slices not only effectively improves the ultimate bearing capacity of the trapezoidal filling structure but also enhances its stability. The effect of reinforcement materials and their layers on the stability of trapezoidal filling structure slope were studied. As shown in Figure 12(a), it is found that the failure surface of the pure concrete granular trapezoidal filling structure runs through the whole trapezoidal filling structure slope. According to the test results and phenomena, the crack characteristics of the lower part of the slope are not obvious when the trapezoidal filling structure of concrete granular reinforced with tire slices is damaged, and the continuous sliding surface can only be described according to the obvious crack characteristics of the upper part of the slope. As shown in Figures 12(b)-12(d), it can be seen that the failure surface of the trapezoidal filling structure reinforced with tire slices is limited to the upper part of the slope.

From Figure 12, it can be seen that the sliding zone of the pure concrete granular trapezoidal filling structure slope is larger than that of the reinforced trapezoidal filling structure slope, but the stable zone is smaller. For the trapezoidal filling structure slope reinforced with singlelayer tire slices, the existence of tire slices prevents the sliding surface from developing towards the interior of the trapezoidal filling structure and forces the sliding surface to develop towards the unreinforced area with lower strength. Therefore, the continuous sliding surface of the trapezoidal filling structure slope reinforced with tire slices is smaller than that of the pure concrete granular trapezoidal filling structure slope. When the stability zone of trapezoidal filling structure is subjected to load, lateral deformation occurs, which promotes the lateral displacement of the soil in the sliding zone. However, the curved tire slices can effectively restrain the lateral deformation of the model. Therefore, the sliding zone is reduced, the stability zone is enlarged, and the stiffness of the stability zone is greatly improved, thereby enhancing the stability of the trapezoidal filling structure slope.
For the trapezoidal filling structure slope reinforced with multilayer tire slices, the stiffness of the lower part of the trapezoidal filling structure slope is significantly increased by increasing the number of reinforcement layers, and the wrapping force is increased by increasing the tire slices. The bearing capacity and stability of trapezoidal filling structure slope are improved, the development of sliding surface to the lower part of slope is effectively prevented, and the continuous sliding surface is limited to the upper part of the slope instead of the whole slope. It can be concluded that increasing the number of tire reinforcement layers can effectively reduce the effect of sliding body on the stability of trapezoidal filling structure slope, so as to achieve the purpose of enhancing the stability of trapezoidal filling structure slope.

Many researchers have made great achievements on the study of ultimate bearing capacity of foundation reinforced with single-layer geocell. Different researchers have deduced different calculation formulas according to different research areas. Generally, researchers mainly divide the ultimate bearing capacity of foundation reinforced with geocell into two kinds: the ultimate bearing capacity of foundation without reinforcement and the ultimate bearing capacity of foundation reinforced with geocell. The latter is mainly influenced by the constraints of geocell, stress dispersion, and membrane effect, which enhance the bearing capacity. With the reinforcement, the carrying capacity is expressed by the following formula:

$$
P_{r}=P_{u}+I
$$

where $P_{r}$ is the ultimate bearing capacity of reinforced foundation, $P_{u}$ is the ultimate bearing capacity of unreinforced soil foundation, and $I$ is the bearing capacity increased by the action of tire plate reinforcement.

The bearing capacity of foundation increases with the increase of the width and depth of foundation. Therefore, the bearing capacity of foundation should be revised according to different width and depth of foundation. The Chinese Code for Design of Building Foundation [26] recommends that when the width of foundation is greater than $3 \mathrm{~m}$ or the depth of embedment is greater than $0.5 \mathrm{~m}$, the eigenvalues of bearing capacity of foundation determined by load test, in situ tests and empirical values should be revised according to the following formula:

$$
f_{a}=f_{a k}+n_{b} \gamma(b-3)+n_{d} \gamma_{m}(d-0.5),
$$

where $f_{a}$ is the modified eigenvalue of bearing capacity of foundation, $f_{a k}$ is eigenvalue of bearing capacity of foundation, $n_{b}$ and $n_{d}$ are modification coefficient of bearing capacity of foundation with Foundation width and depth, $\gamma$ is the gravity of the soil below the foundation and the floating gravity below the groundwater level, $b$ is when the base width is less than $3 \mathrm{~m}$, the base width is $3 \mathrm{~m}$, and when the base width is larger than $6 \mathrm{~m}$, the base width is $6 \mathrm{~m}, \gamma_{m}$ is the weighted average gravity of the soil above the base and the floating gravity below the groundwater level are calculated, and $d$ is the foundation embedding depth $(m)$, which is generally calculated from outdoor elevation. 


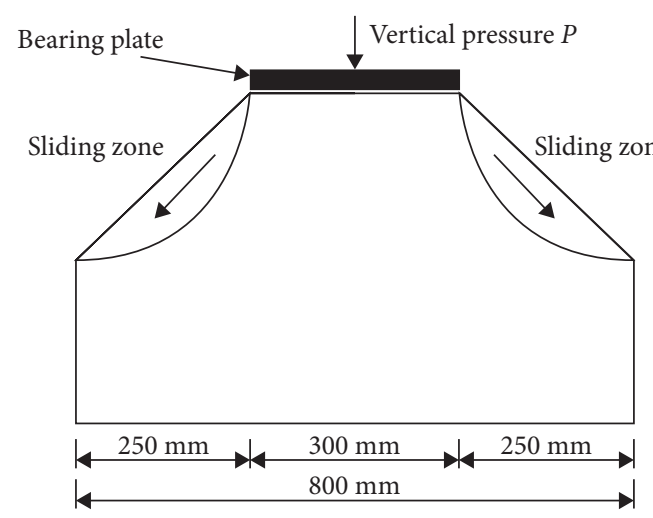

(a)

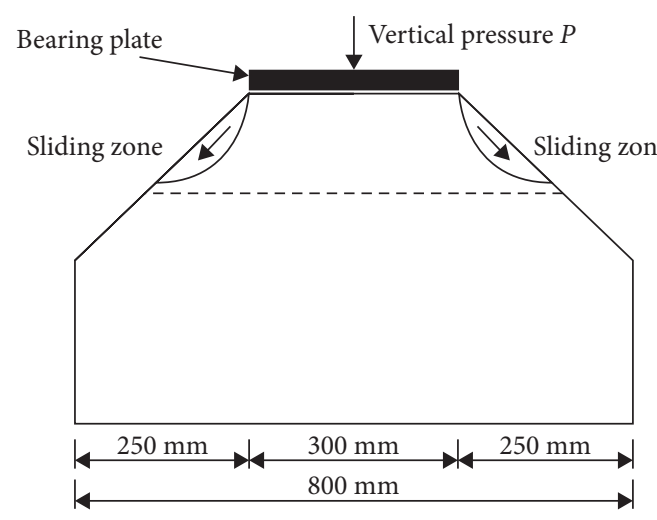

(c)

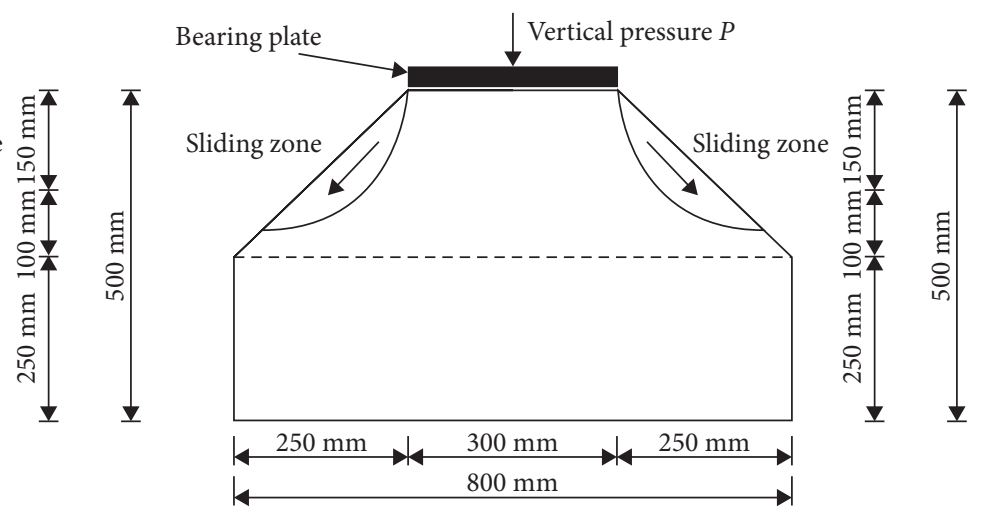

(b)

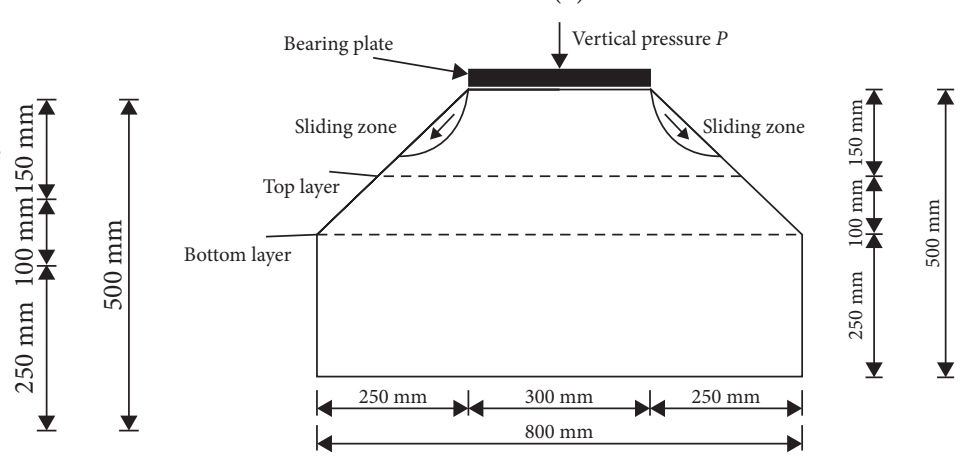

(d)

FIGURE 12: Failure model diagram of trapezoidal filling structure. (a) Failure model of pure concrete granular trapezoidal filling structure. (b) Failure model of bottom layer reinforced trapezoidal filling structure. (c) Failure model of top layer reinforced trapezoidal filling structure. (d) Failure model of two layers reinforced trapezoidal filling structure.

\section{Mechanism Analysis}

The mechanism of the tire slices reinforced concrete particles has been explained by Ma [25]. As concrete particles are irregular-shaped particles, there are a lot of voids among concrete particles without external forces. With vertical loads, the relative displacement of concrete particles will occur. At the same time, the particles will also be extruded, broken, and interlaced. As shown in Figures 13(a) and 13(b), when particles move in relative motion, two kinds of uneven particles may have mosaic effect after relative sliding. Mosaic effect not only increases the friction and cohesion between particles in the sample but also fills the voids among the particles, the internal voids among the concrete particles will be decreased, and the bonding of concrete particles will become tight.

As shown in Figures 14(a) and 14(b), when trapezoidal filling structure of concrete particles is reinforced with tire slices, the curved tire slices will exert wrapping force on the concrete particles. When concrete particles are wrapped by the tire slices, the interaction between tire slices and concrete particles will produce friction force, and the wrapping force and friction will play a role in slope reinforcement.

When trapezoidal filling structure is subjected to external loads, the interaction between concrete particles, concrete particles, and tire slices will occur, and the stiffness of concrete particles is much greater than that of tire slices, which will penetrate into the tire slices after loading. At this time, concrete particles are subject to the reaction force of tire slices, and the cohesion and friction among the model will increase. When the concrete particles reinforced with tire slices are subjected to force, the combination of concrete particles and tire slices will be closer, and the stiffness of tire slices is much lower than that of concrete particles. The external force will cause the surface of tire slices change along the concave and convex surface of concrete and fill the voids between concrete particles; finally, internal combination of trapezoidal filling structure is closer.

The action mechanism of concrete granular trapezoidal filling structure reinforced with tire slices under external loads is shown in Figure 15. The stress state of particles in subgrade is different from its ideal state. Under the perfect condition, the horizontal and vertical pressures acting on particles are $\sigma_{1}$ and $\sigma_{3}$, while in the initial stage of the loading test, additional stresses $\Delta \sigma_{1}$ and $\Delta \sigma_{3}$ appear.

For the instantaneous elastic deformation of soil, as shown in Figure 15(a), although the deformation occurs, the volume of soil does not change $(\Delta \mathrm{V}=0)$, and the effective principal stresses in the horizontal and vertical directions are as follows: 


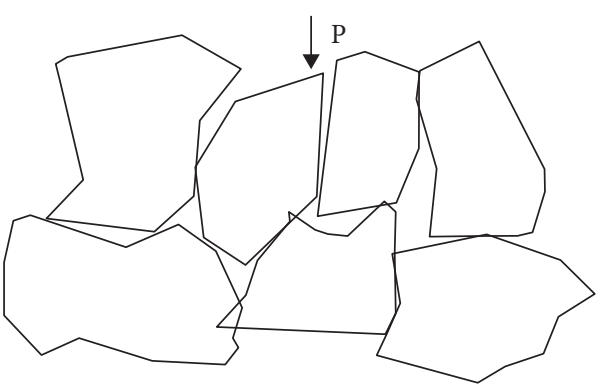

(a)

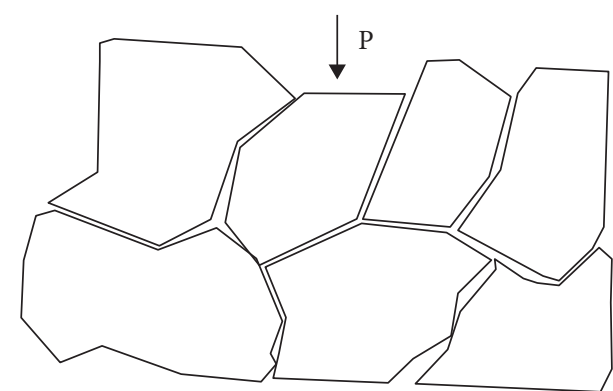

(b)

FIGURE 13: Changes of concrete particles under external loads.

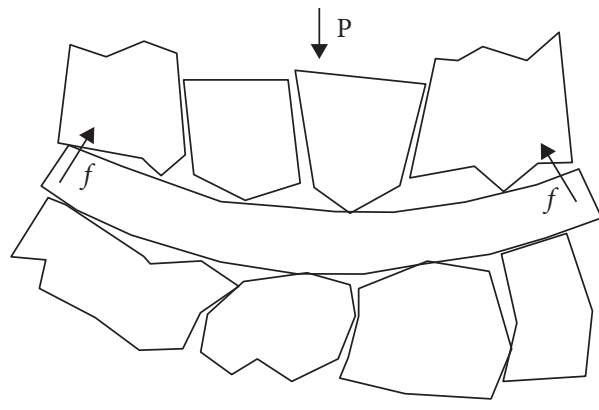

(a)

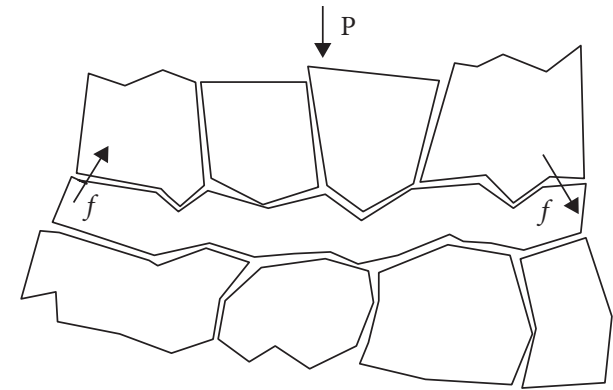

(b)

Figure 14: Changes of external loads on tire slices reinforced concrete particles.

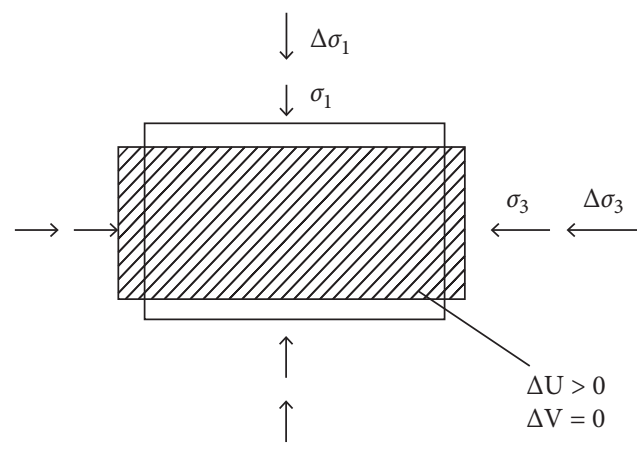

(a)

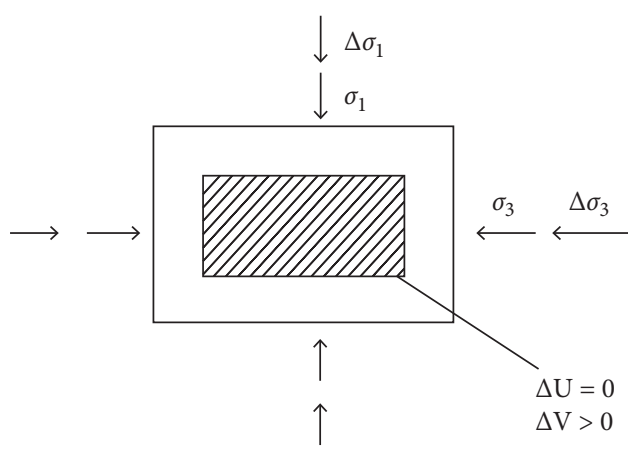

(b)

Figure 15: Micromechanism of lateral deformation of soil.

$$
\left\{\begin{array}{l}
\sigma_{1}^{\bullet}=\sigma_{1}+\Delta \sigma_{1}-\Delta U \\
\sigma_{3}^{\bullet}=\sigma_{3}+\Delta \sigma_{3}-\Delta U
\end{array},\right.
$$

where $\Delta \mathrm{U}$ is the increment of pore water pressure. When $\Delta \mathrm{U}=0$, the effective stress is

$$
\left\{\begin{array}{l}
\sigma_{1}^{\bullet}=\sigma_{1}+\Delta \sigma_{1} \\
\sigma_{3}^{\bullet}=\sigma_{3}+\Delta \sigma_{3}
\end{array}\right.
$$

The comparison between formulas (5) and (6) shows that the value of $\sigma_{3}$ increases more than that of $\sigma_{1}$ in consolidation process $\left(\sigma_{1}>\sigma_{3}\right)$. The trapezoidal filling structure first expands in the horizontal direction and further compresses the trapezoidal filling structure in the vertical direction. Therefore, the effect of horizontal lateral deformation should be considered in deformation calculation.

In the experiment process of this paper, the lateral constraint of the trapezoidal filling structure model without reinforcement is very small, $\sigma_{3}$ is very small and tends to 0 , which is equivalent to unconfined compression, and its strength is very small from (5) and (6). When the trapezoidal filling structure model reinforced with tire slices, lateral restraint force occurs and $\sigma_{3}$ greatly increases. Under the condition of constant $\sigma_{1}$, the strength of the model is greatly improved, which plays the role of strengthening the trapezoidal filling structure model. 


\section{Conclusion}

A series of model tests about the trapezoidal filling structures filled with tire reinforced concrete particles was conducted to study their stability and the ultimate bearing capacity. The effects of the reinforcing tire slices on the global stability and ultimate bearing capacity of the model were investigated. The main conclusions are as follows:

(1) Reinforcement can reduce the total settlement of the trapezoidal filling structure slope. The settlement of the bottom layer of crushed concrete particles reinforced with waste tire slices is $11.5 \%$ less than that of unreinforcement. The settlement of the top layer of crushed concrete particles reinforced with waste tire slices is $37.7 \%$ less than that of unreinforcement. The settlement of the two layers of crushed concrete particles reinforced with waste tire slice is $46.2 \%$ less than that of unreinforcement.

(2) The ultimate bearing capacity of reinforced trapezoidal filling structure with tire slices is obviously improved. Compared with unreinforcement, the Earth pressure values at the top and bottom layers reduced by $21.1 \%$ and $22.7 \%$, respectively, in the condition of the top layer reinforced with tire slices, $6.3 \%$ and $14.3 \%$, respectively, in the condition of the bottom layer reinforced with tire slices, and 23.4\% and $32.9 \%$, respectively, in the condition of the two layers reinforced with tire slices. The effect of the top layer reinforced with tire slices is better than that of the bottom layer, and the effect of the two layers is the best.

(3) The sliding surface of the pure concrete granular trapezoidal filling structure is continuous and runs through the whole trapezoidal filling structure slope, while the continuous sliding surface of the reinforced trapezoidal filling structure slope with tire slices is limited to the upper part of the slope. The sliding zone of trapezoidal filling structure slope decreases with the laying of tire slices.

\section{Data Availability}

The data used to support the findings of this study are available from the corresponding author upon request.

\section{Conflicts of Interest}

The authors declare that there are no conflicts of interest regarding the publication of this paper.

\section{Acknowledgments}

This work was supported by grants from National Natural Science Foundation of China (NSFC) (Grant no. 52078194) and National Key R\&D Program of China (Grant no. 2016YFC0502208). The authors would like to express their appreciation to these financial assistances.

\section{References}

[1] N. N. Eldin and A. B. Senouci, "Use of scrap tires in road construction," Journal of Construction Engineering and Management, vol. 118, no. 3, pp. 561-576, 1992.

[2] T. B. Edil and P. J. Bosscher, "Development of Engineering Criteria for Shredded Waste Tires in Highway Applications," Final Report GT-92-9 Design Methods, 1992.

[3] P. J. Bosscher, T. B. Edil, and S. Kuraoka, "Design of highway embankments using tire chips," Journal of Geotechnical and Geoenvironmental Engineering, vol. 123, no. 4, pp. 295-304, 1997.

[4] S. Benmebarek, F. Berrabah, N. Benmebarek, and L. Belounar, "Effect of geosynthetic on the performance of road embankment over sabkha soils in Algeria: case study," International Journal of Geosynthetics and Ground Engineering, vol. 1, no. 4, 2015.

[5] Z. Q. Li, R. L. Hu, W. Fu, G. R. Tan, Y. X. Zhou, and R. Q. Yue, "Study on using geogrids to reinforce embankment of expressway," Rock and Soil Mechanics, vol. 29, no. 3, pp. 795-799, 2008.

[6] J. L. Borges and A. S. Cardoso, "Overall stability of geosynthetic-reinforced embankments on soft soils," Geotextiles and Geomembranes, vol. 20, no. 6, pp. 395-421, 2002.

[7] J. J. Zheng, B. G. Chen, Y. E. Lu, S. W. Abusharar, and J. H. Yin, "The performance of an embankment on soft ground reinforced with geosynthetics and pile walls," Geosynthetics International, vol. 16, no. 3, pp. 173-182, 2009.

[8] W. Y. Wu, C. C. Benda, and R. F. Cauley, "Triaxial determination of shear strength of tire chips," Journal of Geotechnical and Geoenvironmental Engineering, vol. 123, no. 5, pp. 479-482, 1997.

[9] M. Ghazavi, "Shear strength characteristics of sand-mixed with granular rubber," Geotechnical \& Geological Engineering, vol. 22, no. 3, pp. 401-416, 2004.

[10] N. Hataf and M. M. Rahimi, "Experimental investigation of bearing capacity of sand reinforced with randomly distributed tire shreds," Construction and Building Materials, vol. 20, no. 10, pp. 910-916, 2006.

[11] G. V. Rao and R. K. Dutta, "Compressibility and strength behaviour of sand-tyre chip mixtures," Geotechnical \& Geological Engineering, vol. 24, no. 3, pp. 711-724, 2006.

[12] J. Wartman, M. F. Natale, and P. M. Strenk, "Immediate and time-dependent compression of tire derived aggregate," Journal of Geotechnical and Geoenvironmental Engineering, vol. 133, no. 3, pp. 245-256, 2007.

[13] B. Mills and J. McGinn, "Design, construction, and performance of a highway embankment failure repaired with tirederived aggregate," Transportation Research Record: Journal of the Transportation Research Board, vol. 2170, no. 1, pp. 90-99, 2010.

[14] D. Meles, A. Bayat, M. Hussien Shafiee, S. Nassiri, and M. Gul, "Investigation of tire derived aggregate as a fill material for highway embankment," International Journal of Geotechnical Engineering, vol. 8, no. 2, pp. 182-190, 2013.

[15] D. Meles, A. Bayat, and D. Chan, "One-dimensional compression model for tire-derived aggregate using large-scale testing apparatus," International Journal of Geotechnical Engineering, vol. 8, no. 2, pp. 197-204, 2013.

[16] D. Meles, D. Chan, Y. Yi, and A. Bayat, "Finite-element analysis of highway embankment made from tire-derived aggregate," Journal of Materials in Civil Engineering, vol. 28, no. 2, Article ID 04015100, 2016. 
[17] D. Meles, Y. Yi, and A. Bayat, "Performance evaluation of highway embankment constructed from tire-derived aggregate using falling weight deflectometer tests," Transportation Infrastructure Geotechnology, vol. 3, no. 3-4, pp. 128-142, 2016.

[18] M. Esmaeili, S. A. Mosayebi, and N. Nakhaei, "Experimental investigation of load-deformation behavior of railway embankment mixed with tire derived aggregates (TDA)," MOJ Civil Engineering, vol. 2, no. 1, p. 00020, 2017.

[19] A. R. Khaloo, M. Dehestani, and P. Rahmatabadi, "Mechanical properties of concrete containing a high volume of tire-rubber particles," Waste Management, vol. 28, no. 12, pp. 2472-2482, 2008.

[20] N. N. Eldin and A. B. Senouci, "Rubber-tire particles as concrete aggregate," Journal of Materials in Civil Engineering, vol. 5, no. 4, pp. 478-496, 1993.

[21] B. Huang, G. Li, S.-S. Pang, and J. Eggers, "Investigation into waste tire rubber-filled concrete," Journal of Materials in Civil Engineering, vol. 16, no. 3, pp. 187-194, 2004.

[22] K. E. Kaloush, G. B. Way, and H. Zhu, "Properties of crumb rubber concrete," Transportation Research Record: Journal of the Transportation Research Board, vol. 1914, no. 1, pp. 8-14, 2005.

[23] A. J. Kardos and S. A. Durham, "Strength, durability, and environmental properties of concrete utilizing recycled tire particles for pavement applications," Construction and Building Materials, vol. 98, pp. 832-845, 2015.

[24] S. L. Rodríguez R, L. S. Hernández H, F. G. Pérez-Gutiérrez, and J. H Díaz A, "Mechanical behavior of reinforced concrete with waste-tire particles under an indirect tensile test," MRS Advances, vol. 4, no. 54, pp. 2931-2937, 2019.

[25] Q. Ma, H. Shu, J. Mou, L. Li, and Z. Zheng, "Large-Scale direct shear test on tire slice reinforced crushed concrete particles," Advances in Materials Science and Engineering, vol. 2020, Article ID 8014830, 8 pages, 2020. 